
\title{
28 Research Square \\ The effect of eight exercises on reaction and response times in older people
}

\section{Helia karimimoghadam}

Kurdistan University of Medical Sciences

Mehrangiz Azmoun Cavan

Kurdistan University of Medical Sciences

Golaleh Karbasi ( $\sim$ gelare_633@yahoo.com )

Kurdistan University of Medical Sciences

\section{Research article}

Keywords: Physical activity, motor performance, older people, reaction time, response time

Posted Date: August 20th, 2020

DOl: https://doi.org/10.21203/rs.3.rs-58738/v1

License: (1) This work is licensed under a Creative Commons Attribution 4.0 International License. Read Full License 


\section{Abstract \\ Purpose}

the physical activities have a lot of effects on the improvement of cognitive and motor performance. The purpose of this study is to survey the effect of exercise and physical activities on the reaction and response times (or durations) in older people.

\section{Methodology:}

the method of the study is casual-comparative and its statistic society were consisted of older people of Sanandaj that among them, 30 inactive persons were randomly selected and 30 active and available persons were also selected and their reaction and response times were measured. The reaction time was measured by the reaction timer made by Takei Company (model YB1000) and response time was measured through the movement and response field test of Nelson's selection. The reaction time was firstly and then the response time was measured. For data analysis from the descriptive statistics, the K-S test and T-independent test were used.

\section{Results}

Kolmogorov - Smirnov test revealed that study results have normal distribution. According to the study results, exercise and physical activity have positive effect on reaction and response times so that the results of $T$ independent test showed that the active group has meaningfully lower reaction time $(P=$ $0.000)$ and response time $(P=0.0 .000)$ than the inactive group.

\section{Conclusion}

the results of this study showed that exercise and physical activities lead to the decrement in reaction and response times through the positive physiological and psychomotor changes.

\section{Introduction:}

The older people are a group of people that along with the great advances in science and technology, especially the development of the health sciences are considered as a growing population with special needs and governments have to pay more and more attention to this group. Statistics globally as well as Iran shows that the elder population is increasing day by day. Since one of the objectives of physical education and sports (or exercise) science is to provide a healthy community life through physical activity at all ages of life, therefore, research on elderly's health effects of physical activity on their motor function is part of the goals of sports science research. The aging is not a disease, but a critical phenomenon in which physiological and psychological changes occur in the body. Although aging is not a pathological 
condition, but has limited physical and mental activity and affects them. Along with age increment and reaching to oldness, many changes occur in conducting motor functions which lead to a decrement in successfulness of their conduction. These destructive changes in motor function is due to the psychological factors associated with aging and disorders in the central nervous system and peripheral physiological systems of the body, Physiologically muscular system, the skeletal system and the body composition. The disruption of motor function in the elder causes individual's inability in performing normal everyday tasks and activities. Two of most important factors in elders' motor performance and function are reaction time (The period between the unexpected actuator appearances to start the motor response) and response time (The period between the unexpected actuator appearances to end of motor response) which are from the important factors in conducting most of physical activities such as common daily activities and exercises like driving, walking, balance and postural control [1, 2, 3].

The conducted research on age-related changes in reaction time and response time have shown that it is shortened from infancy to 20 years old, and then, it will slowly until the 50 decades and after that, it will quickly increase. Many experiments have been conducted on the factors affecting the response time. These effective factors are age, type and kind of actuator (actuators intensity and quality) $[4,5]$ and psychological features and person's personality type [6] which has affection on one's reaction time. In the study literature, many studies have shown that exercise and physical activities reduce the reaction time and speed of information processing in humans. Plesnicar (2004) in studying two groups came to the conclusion that the experimental group after 8 weeks of physical training significantly shortens the simple reaction time compared to the untrained group [7]. Drapper, McMoriss and Part (2010) in other study showed that two experimental groups that have conducted exercises and physical activities with various intensities had also different reaction times so that the group which had higher exercise intensity, had lower selective and simple reaction time [8]. The study indicates that exercise is not only effective on reaction time, But the level and intensity also affects reaction time. Research has shown that increasing the reaction time and information processing speed and improve the international image of regular physical activity in the elderly is also true, so that physical activity improves motor function in these persons $[9,10,11]$. Ansiansson (1980) in a study showed that elders' participation in continuous physical activities lead to decrement in simple and selective reaction and response times so that their reaction and response times were closer to the youths than their inactive elders with the same ages [12]. In another study, McDowell, K. et al (2003) showed that physical activities in elder people lead to increment in information processing speed. In this study to elicit information processing speed, the measurement of simple and selective reaction time was used [10]. About the response time should also be said that the sensory-motor function decrement in elders lead to the decline of movement and increment in movement and response time. In old ages, the speed of doing moves decreases and elder people will face with slowness of movements. Karnan et al (1998) in a study measured the differences related to the age in the accessing and getting motor tasks. In this study that was conducted on two groups of youths with mean age of 26 years old and elders with the mean age of 70 years old, it was observed that older people have longer response time than the youths in all tasks. But, with complexity of tasks, this differences related to the age have been increased [13]. In another study on older people, Lemay M, Bertram CP, Stelmach GE 
(2004) measured the speed and time of hand movement during a guided visual accessibility movement and it was observed that, reaction times of older people is longer youths. They declared that one of the reasons of increasing in response time and decreasing in movement speed among the older people is decrement in speed of processing visual information, especially the movement deceleration at the end of the movement than young people [14]. More research has been done on reaction time and movement speed of the elders have shown that in old age and along with aging, movement speed reduced and the international image increases. The reason of this decrement in movements speed and slowness in doing movements is related to the factors such as decrement in muscle strength, central and peripheral nervous system as well as changes in body composition. As it can be seen, in study literature and subject about older people, the accessing and hand movement tests was used and about response time in older people, the field tests which are require whole body movement were not used, while these used tests in the conducted study are not like the actual situation and daily routines and works and movement, and for reaching this purpose, the tests which include more physical moves must be used. On the other hand, research has been done about the reaction time of the elders; the impact of physical activity has not been studied on them; While the present study, surveys the effect of physical activity on reaction and response times.

\section{Method:}

The statistic society of the study are consisted of all older people higher than 55 years old (55 to 65 years old) in Sanandaj $[9,15,16]$. The statistic samples were selected among those who had not the background of doing considered and even similar tasks. The inactive people were randomly chosen among the persons who had not any continuous physical activity. The active samples were also chosen in the case of accessibility among the older people who have participated in the fitness and sports classes of Physical Education Department in Sanandaj and had continuous physical activity three times a week [17]. The sample size was selected regarding to the Determining sample size formula and also previous similar studies and 30 people were selected for each active and inactive groups. Therefore, the statistical sample size was consisted of 60 people that were in two active and inactive groups and each with 30 samples.

\section{Ethical Considerations}

All the participants were properly informed on the objectives of the research and confidentiality of their information, and they participated in the study voluntarily after fulfillment of the informed consent form. The consent was obtained from all participants or their legal guardians as written form. In addition, this research was approved by the ethics committee of the Kurdistan University of Medical Sciences. We confirmed that all methods were carried out in accordance with relevant guidelines and regulations.

\section{Data collection tool:}

For reaction time measurement, the reaction timer was used. For response time, the movement and response test of Nelson's selection was also used [18]. To measure the response time, the red light 
actuator and the red button were used. The red light actuator was placed in the $80 \mathrm{~cm}$ height of sample. The sample was also placed on a chair and in a comfortable situation. Participants responded to the actuator by the right hand thumb. The samples' hands were placed so on the armrest that in line and in same height with the actuator appearance point. Each sample has done ten tries for getting familiar with the test and device that was not analyzed. Then, they conducted 40 tries and data were recorded $[19,20]$. To prevent the tiredness effect, according to the previous studies, 40 tries of each sample were conducted in two blocks include of 20 tries and with 5 minutes rest $[19,21]$. In order to prevent the predicted time by the subject's actuator, actuator was provided randomly in a range of 2 to 4 seconds [16, 20, and 22]. During the study procedure, samples were entered into the test location in groups consisted of 4 persons and any voices that could lead to disruption in samples' concentration were prevented. For response time, the movement and response test of Nelson's selection was also used [18]. This test is used in domestic and external (or abroad) studies. This test has 0.81 validity coefficient and 0.85 reliability coefficient.

The study procedure is as follows:

- We draw a line by 14 yards (6.12 meters) so that its middle and ends be identified.

- The sample is placed in standing mode on the center line and within 2 to 3 meters in front of him.

- Examiner holds with stopwatch one hand and with the other hand or with the same hand suddenly shows one of two right or left directions and at the same time operates the stopwatch.

- The sample runs speedy on the line and until its end to the direction which examiner has shown and the time of this distance is recorded in second and Hundredth of a second.

- This event is repeated ten times and so the sample should run randomly in the directions 5 times. In the other words, the sample should run 5 times to right direction and 5 times to the left.

- 20 second rest should be considered between each performing.

- The mean of then repetitions is considered as the test record for each sample [23].

As most of the samples were low-educated or illiterate, the information about the sample's age, health, disease background and etc. for each person was completed in the special questionnaire by the researcher. At first, the reaction time test and then Nelson's field test were performed.

\section{Statistical methods:}

In this study, for data categorization and adjustment, the descriptive statistics and for determining the normality of data, Kolmogorov-Smirnov test were used. In order to compare the active and inactive groups about the reaction and response times, independent $T$ test with confidence level of 0.95 was used. For data analysis, the SPSS software (version 21) was also used.

\section{Study results}

In table 1, the results of mean, standard deviation and reaction and response times of samples of two active and inactive groups are shown: 
Table (1): Mean and standard deviation of reaction time and the answers of two active and inactive groups

\begin{tabular}{|lllll|}
\hline Test & groups & numbers & means & Standard deviation \\
\hline Reaction time & Active & 30 & 0.254 & 0.141 \\
\cline { 2 - 5 } & Inactive & 30 & 0.289 & 0.18 \\
Response time & Active & 30 & 2.65 & 0.290 \\
\cline { 2 - 5 } & Inactive & 30 & 3.08 & 0.383 \\
\hline
\end{tabular}

In order to determine the normality of data, Kolmogorov-Smirnov test with confidence level of 0.95 ( $a=$ $0.05)$ was used which results are shown in table 2 :

Table 2: Kolmogorov-Smirnov test for surveying the normality of data of simple reaction time

\begin{tabular}{|llll|}
\hline & & Reaction time & Response time \\
\hline Numbers & & 60 & 60 \\
\hline Considered parameters & Mean & 0.272 & 2.86 \\
\cline { 2 - 4 } & Standard deviation & 0.023 & 0.403 \\
\hline Z amount & & 0.768 & 0.583 \\
\hline Sig & & 0.596 & 0.886 \\
\hline
\end{tabular}

In table 3 , the results of independent T test in confidence level of $0.95(a=0.05)$ is shown which is for comparing the reaction and response times in active and inactive older people that indicate that the active older people have meaningful faster reaction and response times than the inactive group.

Table 3: The independent $T$ test for comparing the reaction and response times in active and inactive older people

\begin{tabular}{|llllll|}
\hline Groups & & Mean & Freedom degree & F & Sig \\
\hline Reaction time & Active & 0.254 & 58 & 0.585 & 0.000 \\
\cline { 2 - 4 } & Inactive & 0.289 & & & \\
\cline { 1 - 3 } Response time & Active & 2.65 & 58 & 2.66 & 0.000 \\
\cline { 2 - 3 } & Inactive & 3.08 & & & \\
\cline { 2 - 3 } & & & & & \\
\hline
\end{tabular}

\section{Discussion:}


Fontani et al (2006) also in a study on volleyball players showed that experienced players had shorter reaction time than the inexperienced and amateur players [24]. These results were also repeated by Barcelose et al (2009). They showed that there is high and negative correlation between exercise experience and reaction time [25]. The results of these studies show that not only exercise and physical activity are effective in reaction time but their intensity is also effective in reaction time. The results of these researches has shown that increasing the reaction time and information processing speed and improve the international image of regular physical activity in the elderly is also true, So that physical activity improves motor function in these persons $[9,10,11]$. The studies have shown that physical activities in older people lead to an increment in information processing speed and decrement in reaction time. In another study, McDowell, K. et al (2003) showed that physical activities in elder people lead to increment in information processing speed using reaction time measurement in both youths and older people, but generally, it can be said that different results have been reported in these studies. The difference between the achieved results in these studies is because of so many factors which affect the reaction time. When a study is conducted about the older people, these interruptive and effective factors will increase. In the current study, as the results of independent $t$ test showed, the reaction and response times of active older people were significantly (or meaningfully) lower than inactive older people that this shows the positive effect of exercise and physical activities on these two important factors. In the study literature, many researches survey the effect of different types of physical activities on reaction time which most of them showed that the physical activity has positive effect on reaction time and causes its decrement. Plesnicar (2004) in studying two groups came to the conclusion that the experimental group after 8 weeks of physical training significantly shortens the simple reaction time compared to the untrained group [7]. On the other hand, physical activity leads to more and faster blood circulation to organs and raises and causes ambient temperature, muscles contract faster and with more power, and executive organs of movement has quicker response and their performance improved [27]. Survey the study literature reveals that exercise and physical activities have positive effect on older people's reaction and response time. As it was said, the movement decline is common along with age increment in elders, but there are ways to prevent this decline. Exercises in late adulthood lead to improvement in movements speed and motor function preservation [28]. In another study on older people, Lemay M, Bertram CP, Stelmach GE (2004) measured the speed and time of hand movement during a guided visual accessibility movement and it was observed that, reaction times of older people is longer youths. They recommended that older people spend more time on visual information processing while they are guiding their hands to the target. They also declared that another reason in increasing the response time and decreasing movement speed in older people is decreasing self-training. In this research, they assessed the information processing speed through selective and simple reaction time [10]. The results of this study have also shown that the reaction time of active older people was always lower than inactive ones that this reaction time decrement is due to the positive effect of exercise and physical activities that these group samples have experienced. The exercise and physical activity lead to the concern decrement of the person while performing an unfamiliar motor task which this leads to the performance speed increment and also reaction time decrement [20]. Magill (2000) believes that exercise activities increase the person's cognitive activities ability and information processing. The growth of these capabilities is due to this 
matter that person makes compatibility with unstable environmental conditions and different motives (or actuators) and as a result, obtains the capability of solving issues and quicker and more correct decisionmaking [22]. The studies have shown that physical activities in older people increase the blood circumstance of central nerve system and useful lifetime of brain cells and also useful and quicker information processing that is one of the most important factors in reaction time decrement. Also physical training can provide the best support against aging of brain cells because of its capability in motivating metabolism, breathing increment and muscular decline and also improve the motor performance and function [2, 29]. The first exported hypothesis of input 1 somehow justifies the slowness of movements along with the age increment and reaching the aging period. This hypothesis declares that performing simple motor acts such as reflection moves or other accessing united moves and things controlling and also postural control and balance which grow in the early of life, resist somehow against the decline along with age increment and cause decline more lately; but more harmonious, targeted or complex movements such as displacement exercise moves and speedy and powerful activities which grow much later than primary and reflection moves get decline much sooner and older people 's performance will be sooner disrupted in these moves [27]. The used field test that was utilized in the current study is moves which are decline sooner; and as it was said, the exercise and physical activities greatly lead to prevention from motor performance decline in older period; therefore, the inactive people got more decline in these moves while active older people, due to the possession of positive effect of exercise and physical activities got lower decline in these moves. They declared that one of the reasons of increasing in response time and decreasing in movement speed among the older people is decrement in speed of processing visual information, especially the movement deceleration at the end of the movement than young people [14]. As it was said, in these studies about older people, the accessing and hand movement tests was used and it was not attempted to survey the quick moves and similar daily and common actual situations; so, in the current study, this subject was surveyed through a motor-field test that was like the actual moves and conditions and also the effect of physical activities was studied and surveyed on response time in older people. There are many factors in the terms of physiology which lead to the decline in motor performance. Along with the age increment, the number of functional nerve fibers and muscular fibers which cause the nerve-dissemination (motor unit) will decrease. Also along with age increment, the number of quick contraction muscular fibers will decrease that these factors lead to the slowness motor performance and especially moves that require quick motor responses. Exercise and physical activities lead to the decrement in reaction and response times through the positive physiological and psychomotor changes that cause the reaction and response times decrement and improve their motor performance; therefore, it's recommended that older people keep their motor performance and prevent from motor decline and problems that are appeared in older ages through conducting exercise activities and having active life. With the exercise, they experience lower decline in these kinds of movements.

\section{Conclusion:}


The results of this study showed that exercise and physical activities lead to the decrement in reaction and response times in older people. According to this subject that reaction and response times are effective and important variables in motor performance and common daily life works in old people, so they have a high importance.

\section{Declarations}

\section{Ethics approval and consent to participate}

This research was approved by the ethics committee of the Kurdistan University of Medical Sciences. The consent we obtained from study participants was written. We confirmed that all methods were carried out in accordance with relevant guidelines and regulations. The consent was obtained from all participants or their legal guardians.

\section{Consent for publication}

Not applicable.

\section{Availability of data and material}

All data generated or analyzed during this study are included in this article.

\section{Competing interests}

The authors declared that they have no competing interests.

\section{Funding}

This research did not receive any specific grant from funding agencies in the public, commercial, or notfor-profit sectors.

\section{Authors' contributions}

All authors of this article contributed same in the conception, design, acquisition, analysis, interpretation of data, and have drafted the work. All authors read and approved the final manuscript.

\section{Acknowledgements}

The authors appreciate for cooperation by colleagues in Kurdistan University of Medical Sciences.

\section{References}

1. Karimi Torghabeh E, Ehsani M, Koozechian H, Mehrabi Y. Effect of 16 Weeks Walking with Different dosages on Psychosocial Function Related Quality of Life among 60 to 75 Years Old Men. Iranian Journal of Ageing. 2011;5(18):21-9. 
2. Gallahue D, Ozmun T. Understanding Motor Development. Six, editor. Tehran: Elmo Harekat Press; 2006. $420-65$.

3. Schmidt RA, Lee TD. Motor Control and Learning. Second, editor. Tehran: Elmo Harakat Press; 2005. $140-65$.

4. Kosinski RJ. A Literature Review on Reaction Time. Clemson University journal. 2008;1(2):2-19.

5. Skurvydas A, Gutnik B, Zuoza AK, Nash D, Zuozien IJ, Mickeviciene DM. Relationship between simple reaction time and body mass index. Journal of comparative Human Biology. 2009;9(60):77-85.

6. Socan G, Bucik V. Relationship between speed of information processing and two major personality dimensions- extroversion and neuroticism. Personality Individ Differ. 1998;3(25):35-48.

7. Plesnicar BK. Measurements of reaction time in clinical practice. Psychotic Disorders Antipsychotics. 2004;7(2):17-24.

8. Draper s, McMorris T, Parker JK. Effect of acute exercise of differing intensities on simple and choice reaction and movement times. Psychol Sport Exerc. 2010;4(11):536-41.

9. Chodzko-Zajko WJ. Physical fitness, cognitive performance, and aging. Medical Science Sports Exercise. 1991;23(7):868-72.

10. McDowell K, Kerick SE, Santa Maria DL, Hatfield BD. Aging, physical activity and cognitive processing: an examination of P300. Neurobiol Aging. 2003;24(2):597-606.

11. Sherwood DE, Selder DJ. Cardiorespiratory health, reaction time and Aging. Medical Science Sports. 1979;11(2):186-9.

12. Aniansson A. Muscle functions in old age with special reference to muscle morphology, effect of training and capacity in activities of daily living. First, editor. Goteborg: University of Goteborg Press; 1980.

13. Carnahan H. Vandervoort AA, Swanson LR. The influence of aging and target motion on the control of prehension. Exp Aging Res. 1998;8(24):289-306.

14. Lemay M, Bertram CP, Stelmach GE. Pointing to an Allocentric and egocentric remembered target in younger and older adults. Exp Aging Res. 2004;30(4):391-406.

15. Taghizadeh N. Effect of Sport and Elderly Activity on Here Position Balance [M.A Dissertation]. Tehran: University of Tehran; 2009.

16. Hassanpour Dehkordi A, Masoudi R, Naderipour A, Pour Mirreza Kalhori R. Effect of Sport Program on Shahre Kurd Elderly Life Quality. Iranian Journal of Aging. 2008;2(6):437-44.

17. Wilmore JH, Costill DL. Physiology of Sport and Exercise. Second ed. second. editor. Tehran: Mobtakeran; 1994. pp. 361-8.

18. Prentice WE. Fitness and Wellness for life. Sixth. editor. McGraw-Hill: WCB; 1999. 58 - 9.

19. Davranche K, Burle B, Audiffren M, Hasbroucq T. Physical exercise facilitates motor processes in simple reaction time performance. Neurosci Lett. 2006;396(1):54-6.

20. Davranche K, Burle B, Audiffren M, Hasbroucq T. Information processing during physical exercise: A chronometric and electromyographic study. Exp Brain Res. 2005;165(4):532-40. 
21. Desai K. Effect of aging on simple reaction time and movement time [MA Dissertation]. New York: State university of New York at Buffalo; 2006.

22. Magill RA. Motor learning: Concept and Application. Second. editor. Tehran: SAMT Press; 2002. pp. 21-34.

23. Hemayattalab R, Gaeini AA. Study of Reflect Power and Action Speed of 11-14 Year Student with Nelsons Test. Olympic. 2002;22(3):49-56.

24. Fontani G, Lodi L, Felici A. Attention in athlete of high and low experience engaged in different open skill sports. Perceptual Motor Skills. 2006;102(1):791-805.

25. Barcelose JL, Morales AP, Maciel RN, Azevedo AM, Silva VF. Time of performance: A comparative study of the motor reaction time among volleyball players. Fitness performance. 2009;8(2):103-9.

26. Watson R. Scientific aspects of aging. Journal of clinical nursing. 2005;14(2):283-94.

27. Spirduso W, Francis K, MacRae P. Physical Dimension of Aging. First. editor. New York: Human Kinetics; 2005. 218 - 21.

28. Payne VG, Isaacs LD. Human Motor Development. Fifth, editor. Boston: McGraw-Hill; 2002. 540 - 62.

29. Haywood KM, Getchell N. Life Span Motor Development. First, editor. Tehran: Avaye Zohur Press; 2005. pp. 345-52.

30. Brawn M, Sinacore D, Ehsani A, Binder E, Holloszy JO, Kohrt WM. Low intensity exercise as a modifier of a physical frailty in older adults. Archive of physical medicine rehabilitation. 2000;81(7):960-65.

31. Frolov AA, Prokopenko RA, Dufosse M, Ouezdou FB. Adjustment of human arm viscoelastic properties to the direction of reaching. Cybern. 2006;94(6):97-109.

32. Gardner RM, Urrutia R, Morrell J, Spinozam T, Gallegos V. physiological arousal of obese persons to food stimuli. Motor Skills. 1988;67(4):804-6.

33. Hodgkins j. influence of age on the speed of reaction and movement in females. J Gerontol. 1962;17(3):385-9.

34. Janoff IZ, Beck LH, Child IL. The relation of somatotype to reaction time, resistance to pain, and expressive movement. J Pers. 1950;18(2):454-60.

35. Jette M, Kerr R, Leblanc JI, Lewis W. The effect of excess body fat on fine motor performance following physical exertion. Space Environ Med. 1988;59(2):340-4.

36. Makishita $\mathrm{H}$, Matunaga K. Difference of drivers' reaction time according to age and mental workload. Accid Anal Prev. 2008;40(5):567-75.

37. Pietrobelli A, Faith MS, Allison DA, Gallagher D, Chiomello G. Body mass index as a measure of adiposity among children, adolescent and elderly, a validation study. Journal of pediatrics. 1998;132(8):204-10.

38. Smith HC, Boyarsky S. The relationship between physique and simple reaction time. J Pers. 1943;12(1):46-53.

39. Stamm R, Stamm M, Thomson K. Role of adolescent female volleyball players, psychophysiological properties and body build in performance of different elements of the game. Perceptual Motor Skills. 
2005;101(1):108-20.

40. Report WT. WHO Technical Report. Geneva: WHO, 1995.

41. Zhu S, Heo M, Plankey M, Faith MS, Allison DB. Associations of body mass index and anthropometric indicators of fat mass and fat free mass with all-cause mortality among women in the first and second National Health and Nutrition Examination Surveys follow-up studies. Ann Epidemiology. 2003;13(4):286-93.

42. Daniel WW. Biostatistics. A Foundation for Analysis in the Health Sciences. Eighth: Georgia State University press; 2007. pp. 186-7.

43. O'Neill DE, Thayer RE, Taylor AW, Dzialoszynski TM. G. NE. Effect of short- term resistance training on muscle strength and morphology in the elderly. Journal of aging Physical Activity. 2000;8(2):312-24. 